\title{
Study on Relation between Hydrodynamic Feature Size of HPAM and Pore Size of Reservoir Rock in Daqing Oilfield
}

\author{
Qing Fang, ${ }^{1,2}$ Jinfeng Chen, ${ }^{2}$ Chunnan Lu, ${ }^{2}$ Dandan Yin, ${ }^{3}$ and Yiqiang $\mathrm{Li}^{3}$ \\ ${ }^{1}$ Northeast Petroleum University, Daqing, Heilongjiang 163318, China \\ ${ }^{2}$ Oil Recovery Plant No. 2, Daqing Oilfield Corp. Ltd., Daqing, Heilongjiang 163256, China \\ ${ }^{3}$ EOR Research Institute, China University of Petroleum-Beijing, Beijing 102249, China
}

Correspondence should be addressed to Yiqiang Li; lyq13504598848@163.com

Received 20 November 2014; Accepted 4 March 2015

Academic Editor: Peter Majewski

Copyright (C) 2015 Qing Fang et al. This is an open access article distributed under the Creative Commons Attribution License, which permits unrestricted use, distribution, and reproduction in any medium, provided the original work is properly cited.

\begin{abstract}
The flow mechanism of the injected fluid was studied by the constant pressure core displacement experiments in the paper. It is assumed under condition of the constant pressure gradient in deep formation based on the characteristic of pressure gradient distribution between the injection and production wells and the mobility of different polymer systems in deep reservoir. Moreover, the flow rate of steady stream was quantitatively analyzed and the critical flow pressure gradient of different injection parameters polymer solutions in different permeability cores was measured. The result showed that polymer hydrodynamic feature size increases with the increasing molecular weight. If the concentration of polymer solutions overlaps beyond critical concentration, then molecular chains entanglement will be occur and cause the augment of its hydrodynamic feature size. The polymer hydrodynamic feature size decreased as the salinity of the dilution water increased. When the median radius of the core pore and throat was 5-10 times of the polymer system hydrodynamic feature size, the polymer solution had a better compatibility with the microscopic pore structure of the reservoir. The estimation of polymer solutions mobility in the porous media can be used to guide the polymer displacement plan and select the optimum injection parameters.
\end{abstract}

\section{Introduction}

Polymer flooding research and application in Daqing oilfield has achieved significant economic effect [1]. Polymer flooding has gradually become the main EOR technology for stable production [2,3]. Polymers for displacement were some random coils consisted of one or several polymer molecules in the solution [4]. The molecular coil size of polymer after hydration was defined as hydrodynamic feature size. The polymer hydrodynamic feature size was influenced by such factors as relative molecular mass, concentration, and ion concentration of the sample water $[5,6]$. The larger the polymer hydrodynamic feature size, the more powerful the capability in controlling the mobility in the reservoir. But in the factual displacement, the polymer size was limited by the pore and throat size when flowing. If the polymer hydrodynamic feature size was larger than the pore and throat size, the migration distance of polymer into the core was short under the normal injection pressure; as a result the displacement was invalid [6, 7]. If the polymer hydrodynamic feature size was smaller than the pore and throat size, it was hard to control the mobility. Improving the polymer displacement effect, expanding the swept volume, and enhancing the utilization level of reserves were essential to the polymer displacement technology. Through the analysis of the compatibility between the polymer hydrodynamic feature size and the pore throat, the research of the compatibility between different polymers and different permeability formations can be achieved. It is significant to the program and development of the polymer displacement project [8, 9]. Current laboratory studies were based on the constant speed flooding, which ignores the pressure distribution, for example, funnel between production wells and injection wells. Pressure gradient on near wellbore is larger with faster pressure drops and the injected fluid flow rate was higher. On the other hand, pressure gradient on far wellbore is smaller with slower pressure drops and the injected fluid flow rate was lower. Hence, the question is, can polymer be injected 
TABLE 1: The ionic composition of experimental water (mg/L).

\begin{tabular}{lcccccccc}
\hline Water & \multicolumn{4}{c}{ Ion concentration, $\mathrm{mg} / \mathrm{L}$} & \multicolumn{2}{c}{ Salinity, mg/L } \\
Ions & $\mathrm{K}^{+}, \mathrm{Na}^{+}$ & $\mathrm{Ca}^{2+}$ & $\mathrm{Mg}^{2+}$ & $\mathrm{Cl}^{-}$ & $\mathrm{SO}_{4}{ }^{2-}$ & $\mathrm{HCO}_{3}^{-}$ & $\mathrm{CO}_{3}{ }^{2-}$ & 16.79 \\
Clear water & 73.93 & 39.32 & 17.22 & 54.79 & 31.41 & 236.61 & 15.51 & 468.79 \\
Sewage & 1700.14 & 45.87 & 7.95 & 812.65 & 20.94 & 2886.58 & 186.15 & 5660.29 \\
\hline
\end{tabular}

into near wellbore without contributing effectively on deep reservoir in terms of flow rate?

In this paper, different permeability cores and polymers for displacement in Daqing oilfield were used as examples. Under the condition of current pressure gradient $0.05 \mathrm{MPa} / \mathrm{m}$ in deep reservoir and using the constant pressure displacement, the compatibility between polymer hydrodynamic feature size and pore throat size was researched.

\section{Experiment}

\subsection{Experiment Materials}

(1) Experimental Model. It was the artificial rectangular cores; the size was $4.5 \mathrm{~cm} \times 4.5 \mathrm{~cm} \times 30 \mathrm{~cm}$ and the effective permeability was, respectively, 150, 200, 300, 600 , and $900 \times 10^{-3} \mu \mathrm{m}^{2}$.

(2) Experimental Water. There are two types of experimental water, the clear water and the sewage. The water and the sewage were from the second production plant of Daqing oilfield and the salinity and ionic composition were displayed in Table 1.

(3) Polymers. From the second production plant of Daqing oilfield, the molecular weights were 800,1500 , 1700, and 2500 million.

(4) Experiment Temperature. The temperature of $45^{\circ} \mathrm{C}$ is simulated in deep reservoir of second production plant of Daqing oilfield site.

\subsection{Experimental Procedures and Methods}

2.2.1. Solution Preparation. The mother solutions $(5000 \mathrm{mg} /$ L) were made by dispersing the different molecular weights of polymers into the injected water and then allowing the solutions to stand for 4 hours. According to the experimental requirements, it was diluted to different concentrations and sheared for $10 \mathrm{~s}$ using 5-level Waring blender simulated borehole. In this study, artificial cores were used and the polymer solutions to be evaluated were injected into the core and the pressure gradient has risen from $0 \mathrm{MPa} / \mathrm{m}$ to $0.05 \mathrm{MPa} / \mathrm{m}$. If the outlet flow is bigger than $0.03 \mathrm{~mL} / \mathrm{min}$ under such pressure gradient, it would be defined as the flow pressure gradient in the certain permeability. If measured flow pressure gradient can be lower than the actual pressure gradient in deep reservoir, the polymer solution was considered injectable in the reservoir. If the measured flow pressure gradient was higher than the actual pressure gradient in deep reservoir, the injection properties of polymer solution were poor and the injection parameters should be modified to adjust the reservoir.
2.2.2. Viscosity Measurement. The viscosity of polymer solution was tested in the shear rate of $7.341 / \mathrm{s}$ under $45^{\circ} \mathrm{C}$.

\subsubsection{Polymer Hydrodynamic Feature Size Measurement.} The principle of the polymer hydrodynamic feature size measurement using Millipore filter method was as follows: under the reservoir condition, measure the concentration and viscosity of filtrate using microspore filter in different size. The characteristic of polymer hydrodynamic feature size was determined by the turning point in curve that shows that the concentration and viscosity of filtrate vary as the aperture of microspore filter changes. Pore size of Millipore filter is $0.22 \mu \mathrm{m}, 0.3 \mu \mathrm{m}, 0.45 \mu \mathrm{m}, 0.6 \mu \mathrm{m}$, and $1.0 \mu \mathrm{m}$, respectively. Device for testing hydrodynamic feature size was shown in Figure 1.

2.2.4. Mobility Experiment. According to the oilfield calculation experience, the polymer solution actual flow rate in area of deep reservoir was about $0.3 \mathrm{~m} / \mathrm{d}$. If converted to the experimental core, it was $0.03 \mathrm{~mL} / \mathrm{min}$. In other words, if the flow rate was $0.03 \mathrm{~mL} / \mathrm{min}$, it was stable. The experiment steps are as follows.

(1) Permeability was measured by using nitrogen.

(2) The core was vacuumed and saturated with formation water. Pore volume was then measured.

(3) Polymer solution was prepared by using $0.45 \mu \mathrm{m}$ microspore filter, and then the solution was sheared with simulating shear apparatus.

(4) Different polymer solution was injected into the core for $5-8 \mathrm{PV}$, until the viscosity of polymer solution at outlet became stable, and at the same time the solution reached adsorption equilibrium in the core.

(5) In the process of injecting the polymer solution, the pressure gradient rises from $0 \mathrm{MPa} / \mathrm{m}$ to $0.05 \mathrm{MPa} / \mathrm{m}$. If the outlet flow was stable under such pressure gradient, it would be defined as the flow pressure gradient in the certain permeability.

\section{Results and Discussion}

\subsection{Analysis of Influence Factor of Hydrodynamic Feature Size}

3.1.1. Influence of Molecular Weight of Polymer on the Hydrodynamic Feature Size. By microspore filter method, the hydrodynamic feature size of polymer solution with the molecular weight of $800,1500,1700$, and 2500 million and the concentration of $1000 \mathrm{mg} / \mathrm{L}$ was measured, and then the curve of relationship between the hydrodynamic feature size 


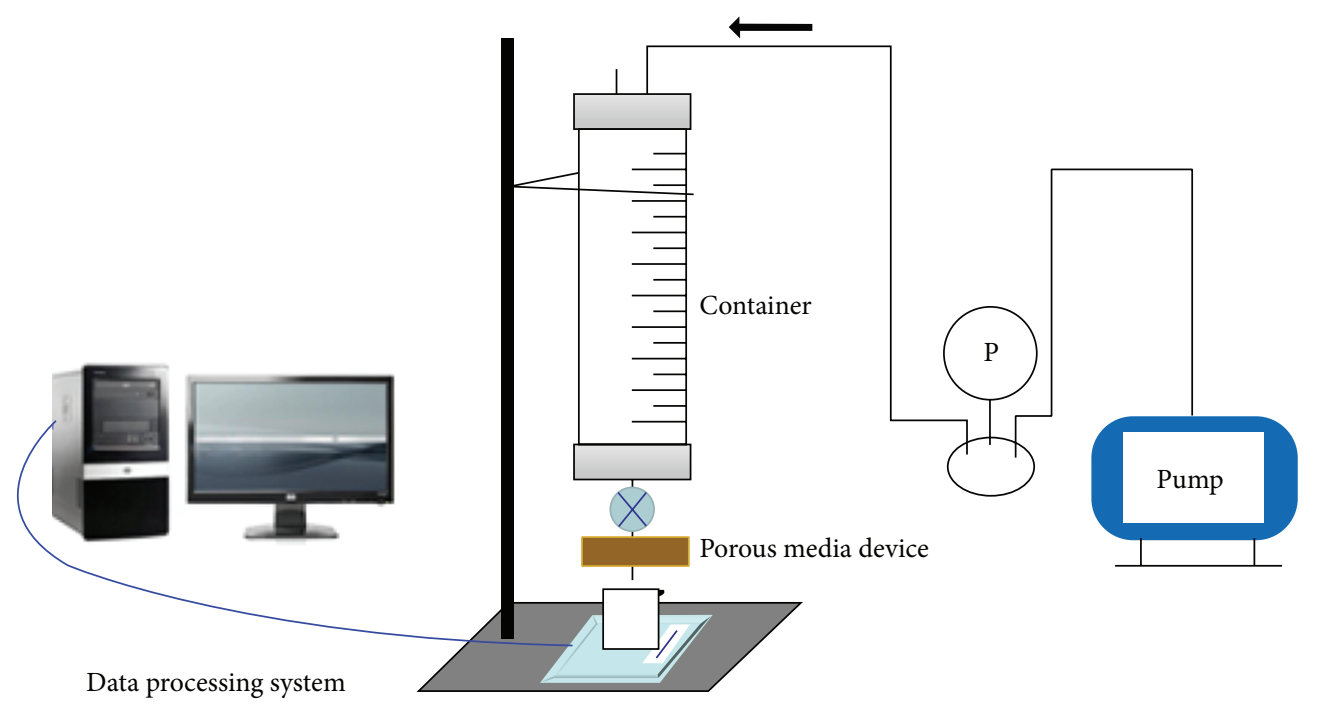

FIgURE 1: Device for hydrodynamic feature size testing.

and the polymer molecular weight was drawn (Figure 3). As Figure 2 shows, in the certain concentration, the polymer molecular weight rose from $800 \mathrm{MW}$ to $2500 \mathrm{MW}$, and the hydrodynamic feature size rose from $0.34 \mu \mathrm{m}$ to $0.53 \mu \mathrm{m}$. As the polymer molecular weight becomes larger, repeat link makes more hydrophilic groups. These hydrophilic groups were solvated; a water sheath was formed outside the polymer which increased the friction in the relative movement. At the same time, ionic hydrophilic group dissociated in the water and generated certain electrical links, which made the polymer expand the molecular chains. The molecules were entangled with each other and became large molecular line group which made it only go through large size microspore filter.

3.1.2. Influence of Concentration of Polymer Solution on the Hydrodynamic Feature Size. By microspore filter method, the hydrodynamic feature size of polymer solution with the concentration of 500,1000,1500, 2000, and $2500 \mathrm{mg} / \mathrm{L}$ and the molecular weight of 1000 million was measured, and the curves of relationship between the hydrodynamic feature size and the concentration of polymer solution were drawn (Figure 3). In the certain polymer molecular weight, the concentration rose from $500 \mathrm{MW}$ to $2500 \mathrm{MW}$, and the hydrodynamic feature size rose from $0.25 \mu \mathrm{m}$ to $0.82 \mu \mathrm{m}$, as shown in Figure 4. When the concentration rose from $500 \mathrm{mg} / \mathrm{L}$ to $1000 \mathrm{mg} / \mathrm{L}$, the hydrodynamic feature size rose a little. When the concentration rises to $1000 \mathrm{mg} / \mathrm{L}$, the hydrodynamic feature size rose linearly. When the concentration was lower than the critical overlap concentration, the number of polymer molecules in unit volume was small and the polymer coils separated. When the concentration rose to some certain degree, the polymer coils were entangled with each other. The polymer size in the solution is concerned with relative molecular mass, structure, and concentration.

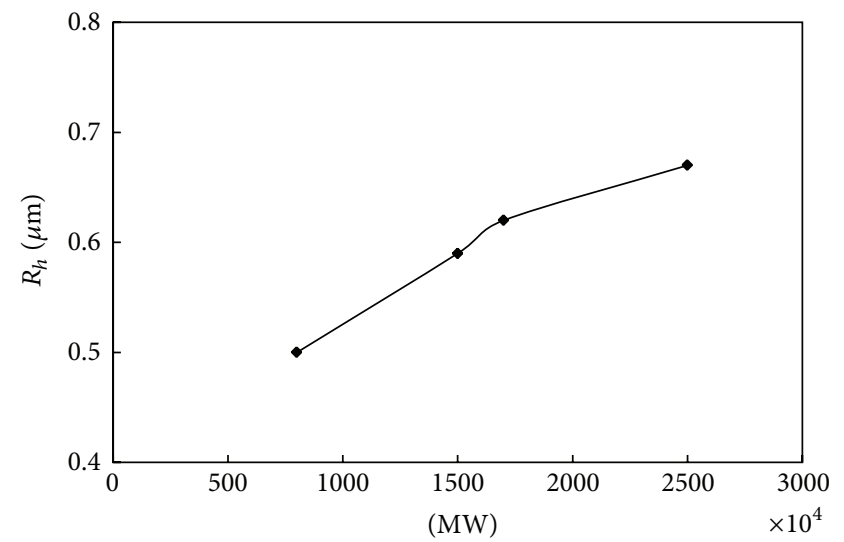

FIGURE 2: Relation between the hydrodynamic feature size and the polymer molecular weight.

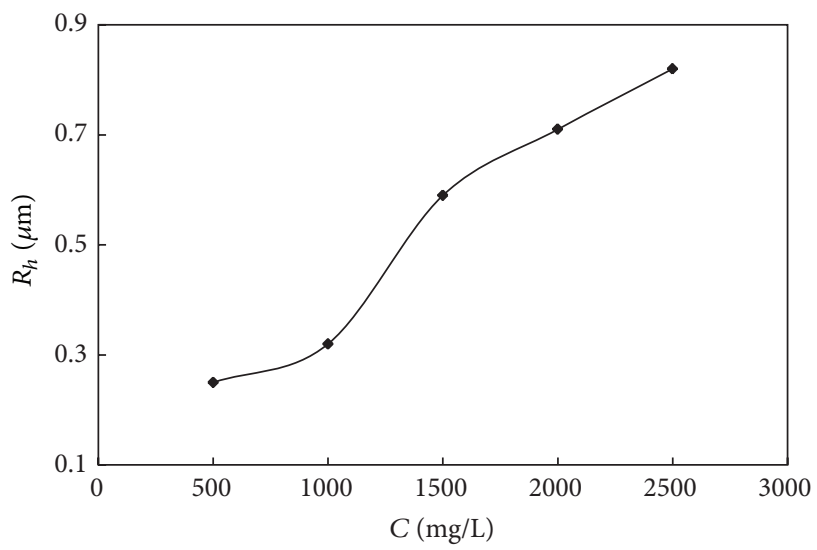

FIgURE 3: Relation between the hydrodynamic feature size and the concentration of polymer solution. 


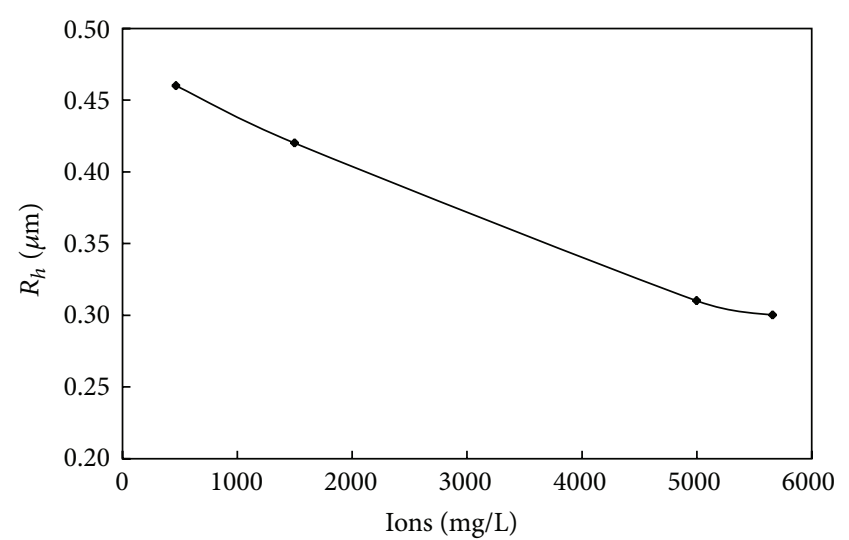

FIGURE 4: Relation between the hydrodynamic feature size and the water salinity.

3.1.3. Influence of Ion Composition on the Polymer Hydrodynamic Feature Size. By microspore filter method, the hydrodynamic feature size of polymer solution (with the molecular weight of 1500 million and the concentration of $1000 \mathrm{mg} / \mathrm{L}$ ) was measured with different water salinity, and then the curve of relationship between the hydrodynamic feature size and the water salinity was drawn (Figure 4). The hydrodynamic feature size decreased as the water salinity increased, as shown in Figure 5. When the partially hydrolyzed polyacrylamide is solved in water, electrostatic repulsion and hydration made the polymer chains stretched; adding mineral salts can reduce the electrostatic repulsion and made the polymer coils huddle. The mechanism was that metal cations neutralized negatively charged carboxyl and formed electrostatic shielding to make the polymer coils huddle, and then the inorganic ions made the molecular hydration and ion dehydration, so that molecules curled.

\subsection{Mobility Experiment}

3.2.1. The Theoretical Basis of the Constant Pressure Experiment. Currently, most of the laboratory displacement experiments were based on constant speed which is inconsistent with the actual ways of injection in oil field. Because of the big differences in flow conditions of injected systems between the deep formation and the near borehole zones, constant pressure injection experiments were designed to simulate the movement of the injection fluid in deep reservoir and to overcome the defects of the constant velocity injection.

In terms of analytical view, the production wells were considered as sinks and the injection wells were considered as sources for the different flows of oil and water at the bottom of the well.

In assumption of the stable plane radial flow, the expression of the pressure gradient of any point in the reservoir can be derived by Darcy's law:

$$
\frac{d P}{d r}=\frac{P_{e}-P_{w f}}{\ln \left(r_{e} / r_{w}\right)} \frac{1}{r}=\frac{P_{e}-P_{w f}}{r \ln \left(r_{e} / r_{w}\right)},
$$

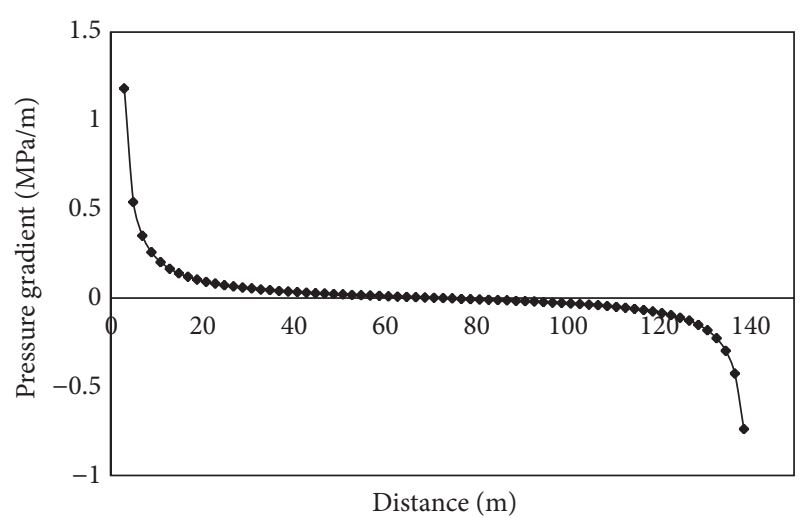

FIgURE 5: Pressure gradient distributions between wells.

where $P_{e}$ is the pressure of injection well, $P_{w f}$ is the pressure of production well, $r_{e}$ is the boundary radius, $r_{w}$ is well radius, and $r$ is percolation radius.

The distributions of the pressure gradients in Daqing oilfield can be calculated by the analytical method (1) and the production data in Daqing oilfield, just as Figure 5 shows. The pressure gradients variation between production wells and injection wells was large, so it is easy to inject. The pressure gradients variation in the deep reservoir was small, so the flow properties (injection) of flooding system will deteriorate at low pressure gradient. The pressure gradients variation curve is drowned by analytical method from injection wells to production wells displayed in Figure 5.

As Figure 5 shows, under the condition of $140 \mathrm{~m}$ well distance, the average pressure gradients of deep area of reservoir were $0.05 \mathrm{MPa} / \mathrm{m}$.

The mobility experiments measured the flow pressure gradient of polymer solution with four kinds of molecular weight and five kinds of concentration in the core with permeability of $150,200,300,600$, and $900 \times 10^{-3} \mu \mathrm{m}^{2}$. The result was shown in Table 2.

If the outlet flow rate was $0.3 \mathrm{~mL} / \mathrm{min}$, it was the effective flow rate in the reservoir and the corresponding pressure gradient would be defined as the flow pressure gradient. Currently, the deep formation pressure gradient is $0.05 \mathrm{MPa} / \mathrm{m}$. If the flow pressure gradient of polymer system is higher than $0.05 \mathrm{MPa} / \mathrm{m}$, the polymer solution will not flow.

As shown in Table 2, to the same polymer system, low permeability required large flow pressure gradient. To the same permeability, flow pressure gradient increased as the molecular weight and concentration decreased. Large molecular weight and high concentration increased the polymer hydrodynamic feature size; it required larger flow pressure gradient in the core. When permeability was $150 \times 10^{-3} \mu \mathrm{m}^{2}$, the polymer system with 800 million molecular weights and $1000 \mathrm{mg} / \mathrm{L}$ concentration could not flow. When permeability was $300 \times 10^{-3} \mu \mathrm{m}^{2}$, part of the system was flow. When permeability was $150 \times 10^{-3} \mu \mathrm{m}^{2}$, all systems were flow. High permeability has big pore and throat; it was easy for the polymer coils to pass through. At the same time, if 
TABLE 2: The result of the flow pressure gradient of different parameter polymer solution in different permeability cores (MPa/m).

\begin{tabular}{|c|c|c|c|c|c|c|c|c|c|c|c|}
\hline \multirow[b]{2}{*}{$\mathrm{MW}, 10^{4}$} & \multirow[b]{2}{*}{$C, \mathrm{mg} / \mathrm{L}$} & \multicolumn{2}{|c|}{$150 \times 10^{-3} \mu \mathrm{m}^{2}$} & \multicolumn{2}{|c|}{$200 \times 10^{-3} \mu \mathrm{m}^{2}$} & \multicolumn{2}{|c|}{$300 \times 10^{-3} \mu \mathrm{m}^{2}$} & \multicolumn{2}{|c|}{$600 \times 10^{-3} \mu \mathrm{m}^{2}$} & \multicolumn{2}{|c|}{$900 \times 10^{-3} \mu \mathrm{m}^{2}$} \\
\hline & & $\begin{array}{l}\text { Clear } \\
\text { water }\end{array}$ & Sewage & $\begin{array}{l}\text { Clear } \\
\text { water }\end{array}$ & Sewage & $\begin{array}{l}\text { Clear } \\
\text { water }\end{array}$ & Sewage & $\begin{array}{l}\text { Clear } \\
\text { water }\end{array}$ & Sewage & $\begin{array}{l}\text { Clear } \\
\text { water }\end{array}$ & Sewage \\
\hline 800 & 1000 & 0.053 & 0.044 & 0.032 & 0.032 & 0.02 & 0.02 & 0.01 & 0.01 & 0.01 & 0.01 \\
\hline \multirow{5}{*}{1500} & 500 & 0.059 & 0.053 & 0.049 & 0.032 & 0.035 & 0.02 & 0.01 & 0.01 & 0.01 & 0.01 \\
\hline & 1000 & 0.065 & 0.061 & 0.054 & 0.049 & 0.04 & 0.032 & 0.014 & 0.012 & 0.014 & 0.012 \\
\hline & 1500 & 0.12 & 0.089 & 0.074 & 0.062 & 0.053 & 0.043 & 0.032 & 0.023 & 0.021 & 0.013 \\
\hline & 2000 & 0.13 & 0.116 & 0.078 & 0.074 & 0.058 & 0.053 & 0.039 & 0.033 & 0.024 & 0.013 \\
\hline & 2500 & 0.157 & 0.12 & 0.09 & 0.094 & 0.068 & 0.069 & 0.045 & 0.04 & 0.034 & 0.021 \\
\hline 1700 & 1000 & 0.07 & 0.065 & 0.06 & 0.052 & 0.047 & 0.036 & 0.017 & 0.019 & 0.013 & 0.013 \\
\hline 2500 & 1000 & 0.078 & 0.072 & 0.072 & 0.058 & 0.062 & 0.043 & 0.034 & 0.032 & 0.013 & 0.014 \\
\hline
\end{tabular}

TABLE 3: The core parameters.

\begin{tabular}{lcccc}
\hline $\begin{array}{l}\text { Number of } \\
\text { the cores }\end{array}$ & $K, \times 10^{-3} \mu \mathrm{m}^{2}$ & $\Phi, \%$ & $r_{50}, \mu \mathrm{m}$ & $r_{h}, \mu \mathrm{m}$ \\
\hline S33-2 & 204 & 25.50 & 2.43 & 4.41 \\
S212-1 & 337 & 29.30 & 2.95 & 4.95 \\
S38-2 & 661 & 31.70 & 5.47 & 5.12 \\
172-5 & 928 & 28.01 & 9.26 & 8.67 \\
\hline
\end{tabular}

TABLE 4: The different polymer system hydrodynamic feature size.

\begin{tabular}{lccc}
\hline MW, $10^{4}$ & $C, \mathrm{mg} / \mathrm{L}$ & \multicolumn{2}{c}{$R_{h}, \mu \mathrm{m}$} \\
\hline 800 & 1000 & 0.34 & Sewage \\
\hline \multirow{3}{*}{1500} & 500 & 0.25 & 0.17 \\
& 1000 & 0.46 & 0.11 \\
& 1500 & 0.59 & 0.3 \\
& 2000 & 0.71 & 0.45 \\
1700 & 2500 & 0.82 & 0.59 \\
\hline 2500 & 1000 & 0.48 & 0.72 \\
\hline
\end{tabular}

the permeability of the reservoir is smaller than $200 \times$ $10^{-3} \mu \mathrm{m}^{2}$, polymer flooding will have no economic benefit.

The corresponding average pore throat radius of different permeability cores based on the mercury experiment was shown in Table 3 . The different polymer system hydrodynamic feature size was shown in Table 4.

In the preparation and adjustment of polymer flooding, choose the fluidity near to the critical point to guarantee the capacity of controlling the fluidity.

S33-2 core permeability was $204 \times 10^{-3} \mu \mathrm{m}^{2}$, pore throat radius value was $2.43 \mu \mathrm{m}$, and critical hydrodynamic feature size for effective flow was $0.25 \mu \mathrm{m}$. S212-1 core permeability was $337 \times 10^{-3} \mu \mathrm{m}^{2}$, pore throat radius value was $2.95 \mu \mathrm{m}$, and critical hydrodynamic feature size for effective flow was $0.45 \mu \mathrm{m}$. S38- 2 core permeability was $661 \times 10^{-3} \mu \mathrm{m}^{2}$, pore throat radius value was $5.47 \mu \mathrm{m}$, and critical hydrodynamic feature size for effective flow was $0.82 \mu \mathrm{m}$. When the pore throat radius value was 5-10 times of the hydrodynamic feature size, the polymer solution was flow. To ensure the proper mobility, choose optimum injection parameters by measuring concentration, water quality, and molecular weight of different polymer solution and the pore throat radius value by the mercury experiment. Above all, the plate formed by this method can be used to choose the proper parameters for the plan and adjust the polymer flooding and optimize the effect of polymer flooding in different reservoirs.

\section{Conclusions}

(1) The hydrodynamic feature size of polymer solution increases with augment of the molecular weight. When the concentration overlaps beyond the critical concentration, the polymer coils are entangled with each other. With higher water salinity, hydrodynamic feature size is getting smaller.

(2) For a certain permeability reservoir, flow pressure gradient of polymer solution decreases with the increasing injection parameters. With lower permeability, flow pressure gradient will be higher.

(3) When pore throat radius value was 5-10 times of hydrodynamic feature size, the polymer solution has flow ability, which can be used to choose the proper parameters for the plan and adjustment of polymer flooding.

\section{Conflict of Interests}

The authors declare that there is no conflict of interests regarding the publication of this paper.

\section{References}

[1] N. Jin-Gang, "Practices and understanding of polymer flooding enhanced oil recovery technique in Daqing oilfield," Petroleum Geology \& Oilfield Development in Daqing, vol. 5, article 024, 2004.

[2] D. Wang, C. Lv, X. Fu, and J. Nie, "Review of practical experience by polymer flooding at Daqing," SPE Reservoir Evaluation \& Engineering, vol. 12, no. 3, pp. 470-476, 2009. 
[3] T. Skauge, K. Spildo, and A. Skauge, "Nano-sized particles for EOR," in Proceedings of the 17th SPE Improved Oil Recovery Symposium (IOR '10), pp. 1281-1290, April 2010.

[4] M.-Y. Li, Z.-X. Dong, M.-Q. Lin, and Z.-L. Wu, "A study on the size and conformation of linked polymer coils," Journal of Petroleum Science and Engineering, vol. 41, no. 1-3, pp. 213-219, 2004.

[5] X. Zhao, L. Liu, Y. Wang, H. Dai, D. Wang, and H. Cai, "Influences of partially hydrolyzed polyacrylamide (HPAM) residue on the flocculation behavior of oily wastewater produced from polymer flooding," Separation and Purification Technology, vol. 62, no. 1, pp. 199-204, 2008.

[6] X.-Q. Han, W.-Y. Wang, and Y. Xu, "The viscoelastic behavior of HPAM solutions in porous media and it's effects on displacement efficiency," in Proceedings of the International Meeting on Petroleum Engineering, pp. 597-614, Society of Petroleum Engineers, November 1995.

[7] S. Guan, H.-F. Fan, S. Wu, and C.-H. Song, "Examination of the concentration of HPAM-the turbidity method," Journal of Daqing Petroleum Institute, vol. 31, no. 2, p. 106, 2007.

[8] D. D. Yin, Y.-Q. Li, F. Dong, F.-Y. Wang, and J.-X. Gao, "Study on matching relationship of polymer hydrodynamic size and pore throat size for stratum in sand reservoir," in Proceedings of the Offshore Technology Conference-Asia, Kuala Lumpur, Malaysia, March 2014.

[9] L. Wenli, M. Desheng, L. Meiqin, L. Gang, N. Xiaobin, and L. Qingxia, "Matching relation between HPAM polymer DQ3500 and pores of reservoir rock," Procedia Engineering, vol. 18, pp. 261-270, 2011. 

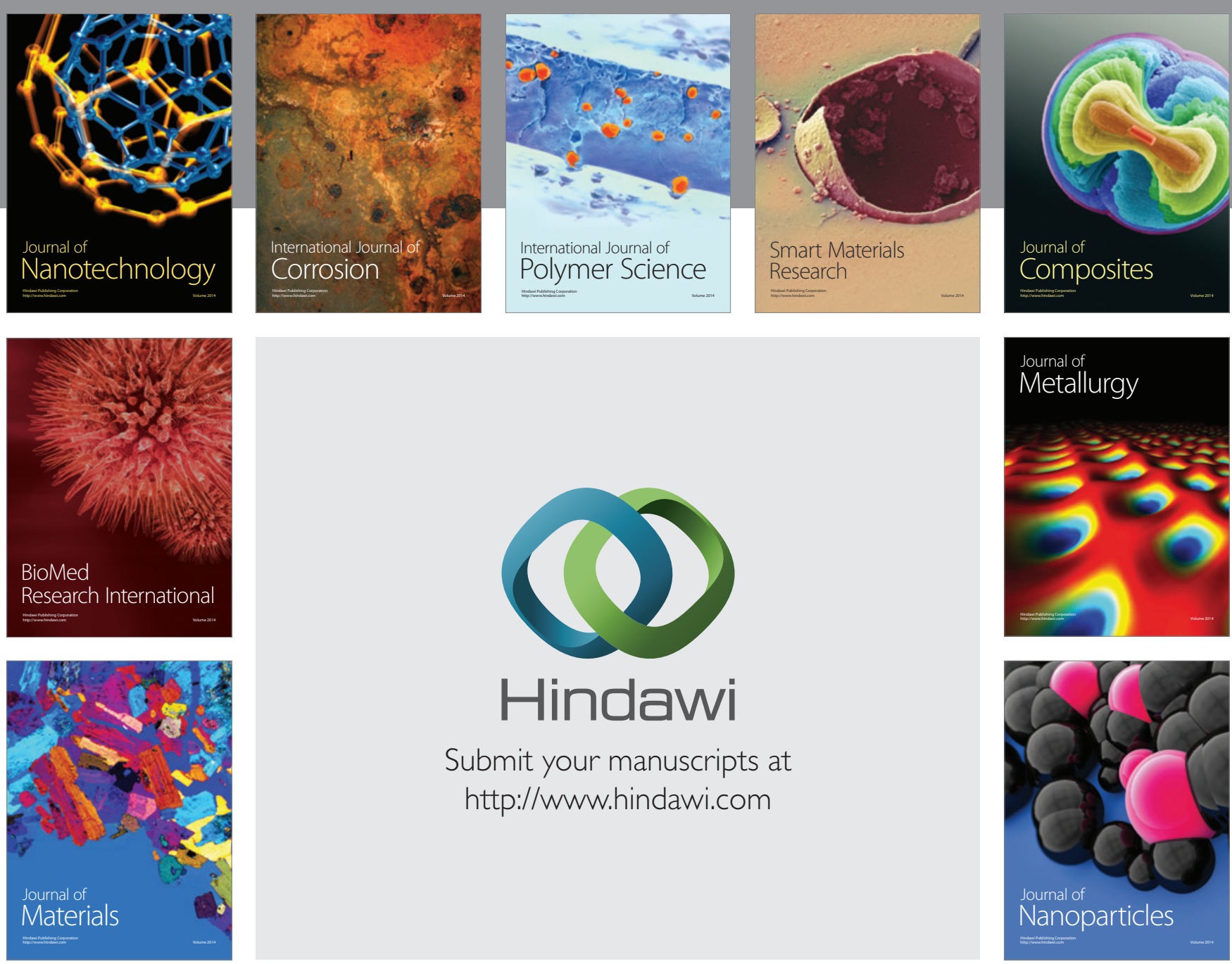

Submit your manuscripts at http://www.hindawi.com
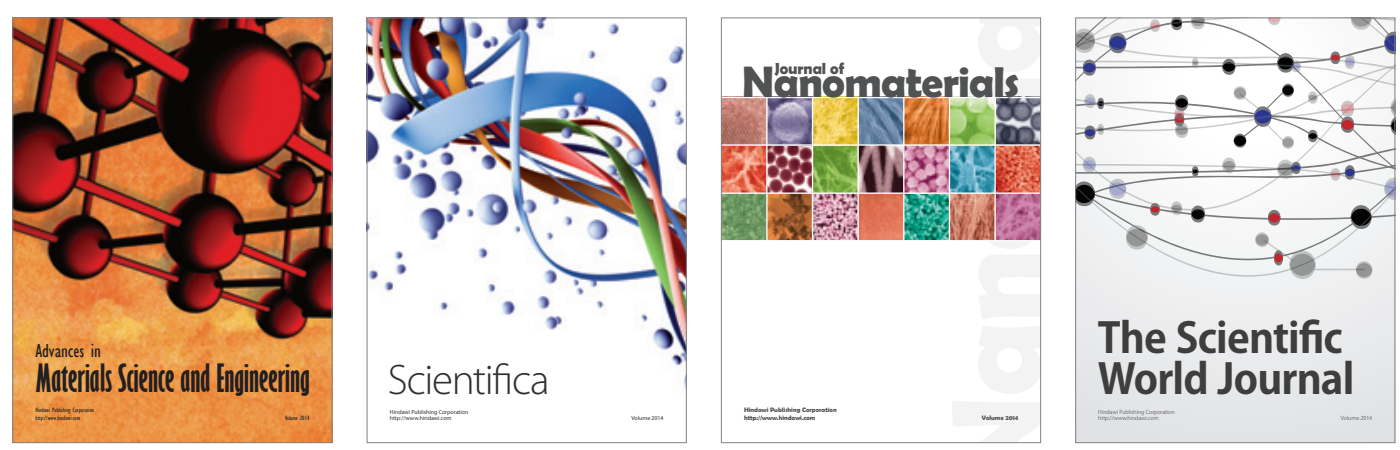

\section{The Scientific World Journal}
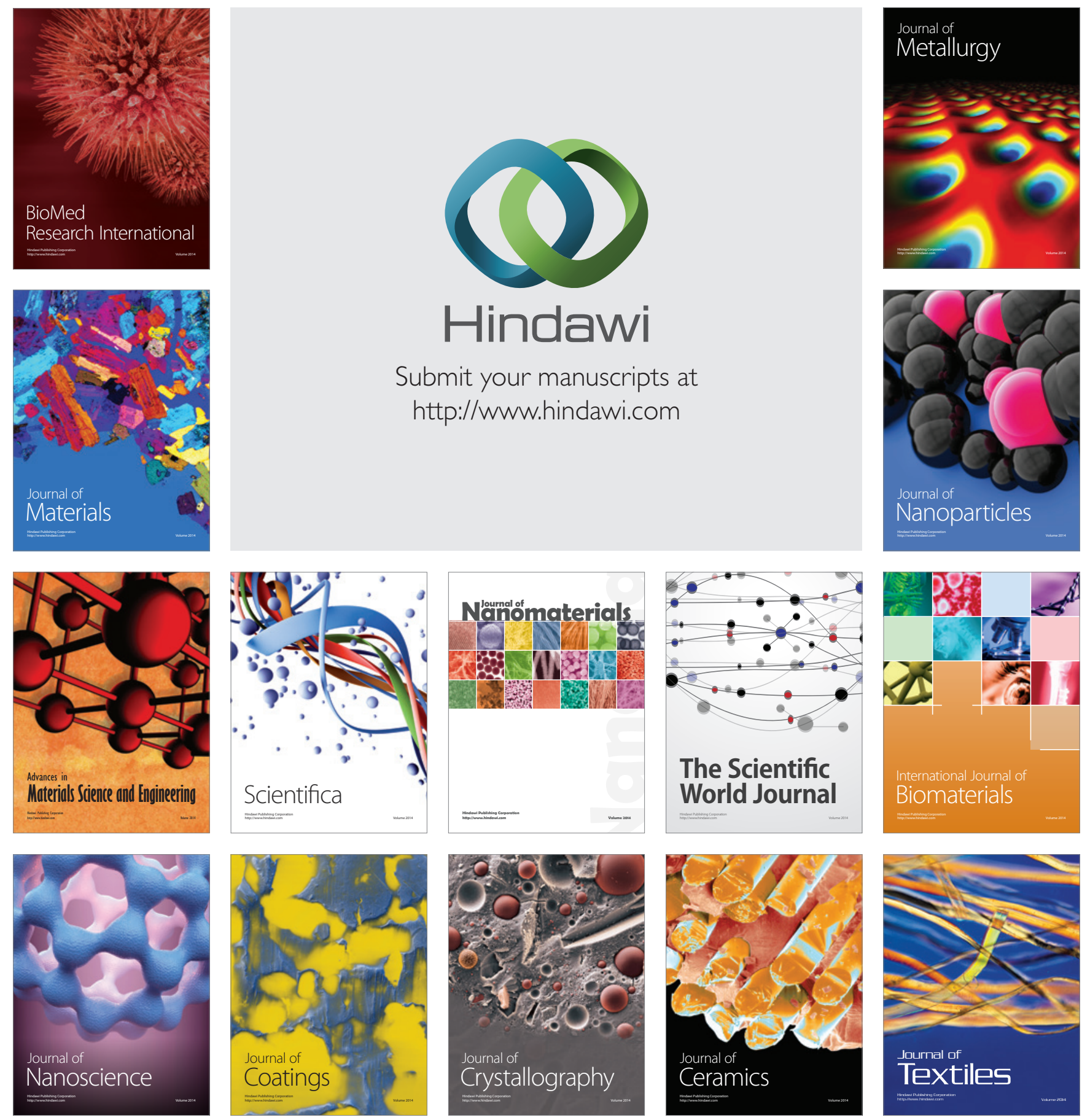